Goldschmidt 2021 Abstract

https://doi.org/10.7185/gold2021.5459

\section{Sulfur cycling the gabbroic section of the Samail Ophiolite Oman}

ANA PATRÍCIA M JESUS ${ }^{1}$, HARALD STRAUSS ${ }^{2}$, DIOGO SILVA $^{3}$, MARIO GONCALVES ${ }^{4}$, MICHELLE HARRIS $^{5}$ AND DAMON TEAGLE ${ }^{6}$

${ }^{1}$ Instituto Dom Luiz/Faculdade Ciencias Lisboa

${ }^{2}$ Westfälische Wilhelms-Universität Münster

${ }^{3}$ Faculdade Ciencias Lisboa

${ }^{4}$ Faculdade Ciencias LIsboa / Instituto Dom LUiz

${ }^{5}$ Plymouth University

${ }^{6}$ University of Southampton

Presenting Author: ana.jesus@fc.ul.pt

We report sulfur geochemistry for the Samail ophiolite, Oman, using samples from the Oman Drilling Project (OmanDP; [1]). Hole GT3 drilled the upper crustal sheeted dike (basalt + diabase) upper gabbro transition. The lower crustal section holes GT2 (foliated-layered gabbro transition) and GT1 (layered gabbro) are mainly composed of olivine (bearing) gabbro. All sections record the effects of hydrothermal metamorphism under decreasing temperatures.

Acid Volatile Sulfides (AVS, e.g. pyrrhotite-Po), CrReducible Sulfur (CRS, e.g. pyrite- $P y$, chalcopyrite-Ccp) and acid-soluble sulfate were analyzed for $\delta^{34} \mathrm{~S}$ at WWU-Muenster (Fig.1). The dike-gabbro transition has significantly higher and more variable $\delta^{34} \mathrm{~S}_{\mathrm{CRS}}$ values $(-12.8 \%$ o to $+13.3 \%$ ) compared to the lower crustal section $(-3.2$ to $+2.3 \%$ ) .

No magmatic sulfides are preserved in GT3. $\delta^{34} \mathrm{~S}_{\mathrm{CRS}}<0$ and low total sulfide sulfur contents $\left(\mathrm{TS}_{\text {Sulfide }}\right)$ relative to MORB suggest that open system sulfur leaching and bacterial sulfate reduction-BSR were dominant in the upper $\sim 80 \mathrm{~m}$. Below, thermochemical seawater sulfate reduction via Fe-oxidation of silicates and magmatic sulfides was the pathway for sulfide formation. Following the maximum ${ }^{34} \mathrm{~S}$-enrichment at $\sim 120 \mathrm{~m}$, values decrease downhole. $\mathrm{TS}_{\text {Sulfide }}$ and ${ }^{34}$ S-enrichments associated to sulfide mineralization may represent localized hydrothermal fluid upflow zones.

Low recovery of $\delta^{34} \mathrm{~S}_{\mathrm{AVS}}(-0.2 \%$ to $+1.9 \%$ ) in the lower crustal section reflects the ubiquitous occurrence of secondary sulfides from recrystallization of primary sulfides or silicates. $\delta^{34} \mathrm{~S}_{\mathrm{CRS}} X=1.2 \%$ o close to MORB implies formation of secondary sulfides did not involve significant $S$-seawater input but redistribution of magmatic sulfur. $\mathrm{TS}_{\text {Sulfide }}$ enrichments in some sections may reflect crystal fractionation processes.

Mass balance for hydrothermal fluid composition in the upper crustal section (lithology integrated excluding BSR, $X \delta^{34} \mathrm{~S}_{\mathrm{CRS}}=$ $+6.3 \%$ ) implies $37 \%(\max =80 \%)$ contribution of seawater; sulfate yielding $\delta^{34} \mathrm{~S}=+4.9 \%$ formed by abiotic oxidation of hydrothermal sulfides. Estimates for seawater contribution in the lower crustal section are low $(X=7 \%$; $\max =12 \%)$ although the occurrence of $\delta^{34} \mathrm{~S}_{\text {sulfate }} \sim 17 \%$ implies precipitation from Cretaceous seawater, conceivably introduced via deep oceanic faults. Preservation of sulfates in the deep crust could be favoured by limited fluid upflow, contrarily to the upper crustal section where open-system circulation prevailed.

[1] Kelemen PB, Matter JM, Teagle DAH, Coggon JA, OmanDP Science Team (2020) Proceedings of the OmanDP: College Station, TX (IODP).
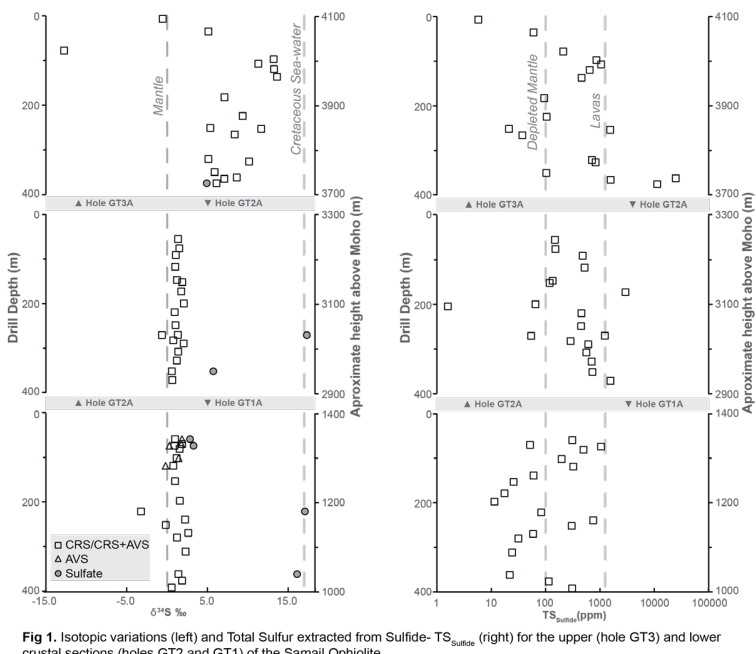

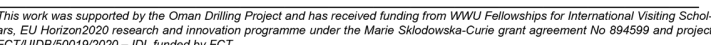

